\title{
COMPETENCIA EN LA MODIFICACIÓN POR TRIBUNALES ESPAÑOLES DE MEDIDAS RELATIVAS A ALIMENTOS ESTABLECIDAS POR TRIBUNALES EXTRANJEROS. COMENTARIO AL AUTO DEL TRIBUNAL SUPREMO DE 17 DE SEPTIEMBRE DE 2019
}

\author{
JURISDICTION AND AMMENDMENTS BY SPANISH COURTS \\ OF MEASURES RELATING TO ALIMONY ESTABLISHED \\ BY FOREIGN COURTS. A COMMENTARY TO THE ORDER \\ OF THE SPANISH SUPREME COURT OF SEPTEMBER 17, 2019
}

\author{
María José Valverde MartíneZ \\ Abogada del Ilustre Colegio de Abogados de Murcia
}

Recibido: 08.01.2020 / Aceptado: 15.01.2020

DOI: https://doi.org/10.20318/cdt.2020.5219

\begin{abstract}
Resumen: La modificación por tribunales españoles de medidas acordadas por tribunales extranjeros es un tema candente por la conjunción de instrumentos normativos de muy diferente índole (europeos, internacionales y nacionales) que han de ser interpretados de forma integrada con el fin de determinar la competencia del órgano jurisdiccional correspondiente. En este estudio se aborda el Auto del Tribunal Supremo de 17 de septiembre de 2019; resolución que resuelve un conflicto negativo de competencia suscitado entre dos tribunales españoles, los cuales declararon su falta de competencia territorial en relación a una demanda de modificación de medidas adoptadas en sentencia de divorcio previamente pronunciada por un juzgado de Rumanía. La modificación de medidas solicitada en la demanda presentada ante los tribunales españoles concernía al importe de la pensión alimenticia de la hija menor de los cónyuges divorciados.
\end{abstract}

Palabras clave: modificación de medidas, pensión de alimentos, divorcio, competencia internacional, competencia territorial de tribunales españoles, conflicto negativo de competencia, Derecho Internacional Privado.

\begin{abstract}
The modification by Spanish courts of measures granted by foreign courts is a difficult topic due to the combination of different regulatory instruments of a very diverse nature (European, international and national). All of them must be interpreted in an integrated manner in order to determine the competence of a specific court. In this study, the Order of September 17, 2019 rendered by the Spanish Supreme Court is analyzed. The order solves a negative conflict of jurisdiction between two Spanish courts, which declared their lack of territorial jurisdiction with regard to a claim of modification of measures adopted in a divorce decree previously pronounced by a Romanian court. The modification of measures was requested before the Spanish courts and concerned the amount of the child support of the daughter of the divorced spouses.
\end{abstract}

Keywords: modification of measures, child support, divorce, international jurisdiction, territorial jurisdiction of spanish courts, negative conflict of jurisdiction, Private International Law. 
Sumario: I. Introducción. Descripción de la cuestión objeto de estudio. II. Primer nivel normativo. Competencia internacional y Reglamento (CE) 4/2009, de 18 de diciembre de 2008. III. Segundo nivel normativo: Competencia territorial de los tribunales españoles. Ley 1/2000, de 7 de enero, de Enjuiciamiento Civil. a) El nuevo marco de competencia territorial del art. 775 LEC, en su redacción ofrecida por la Ley 42/2015, de 5 de octubre. b) La regla de competencia territorial para asuntos con "elementos extranjeros". Entra al terreno de juego el art. 769 LEC. IV. Una realidad alternativa. Los foros del Reglamento 4/2009 como foros de competencia internacional y también territorial. V. Reflexiones finales.

\section{Introducción. Descripción de la cuestión objeto de estudio}

1. La abogacía práctica ha de estar dotada en la actualidad de herramientas capaces de asesorar a los particulares sobre las posibilidades que abre tanto la libre circulación de personas como la libre circulación de resoluciones judiciales en la Unión Europea. Así, una pareja que se dio el "sí, quiero" en Londres pudo establecer con posterioridad su primer domicilio conyugal en Bucarest y, tras el divorcio, uno de los ex cónyuges pudo haber trasladado su residencia habitual a Madrid mientras el otro se trasladaba a Rumanía junto a sus hijos menores. ¿Ante los tribunales de qué Estado debe interponerse una demanda de modificación de los alimentos concedidos a los hijos menores e inicialmente fijados en la sentencia de divorcio dictada por un tribunal londinense?

2. Nunca se insistirá suficientemente en que, tras la crisis matrimonial, cuando termina el matrimonio, la familia no termina. Los cónyuges se divorcian pero los padres no se divorcian de sus hijos. Las relaciones paterno-filiares subsisten más allá del divorcio y las obligaciones por alimentos permanecerán vivas e incluso podrán, y deberán, ser objeto de modificación si se produce una variación sustancial de las circunstancias económicas del alimentante o de las necesidades del acreedor de los alimentos. Por tanto, aquéllas medidas relativas a alimentos que se adoptaron como inicialmente "definitivas" en el divorcio podrán ser modificadas, cuestión que, en la mayoría de las ocasiones, será controvertida y litigiosa y llevará, irremediablemente, a plantear cuál es el juzgado competente para el conocimiento del litigio iniciado para la modificación de dichas medidas.

3. Cuando la modificación de medidas acordadas en una sentencia de divorcio surge en un contexto internacional, la problemática es mayor que en los supuestos internos. En efecto, en los casos transfronterizos, y en orden a determinar cuáles serán los concretos tribunales competentes que conozcan de la indicada modificación de medidas, será necesario realizar una ingente labor integradora entre normas de Derecho Internacional Privado y normas de Derecho nacional. Y junto a ello, de vital importancia será establecer estrategias procesales y de Derecho sustantivo encaminadas a determinar, en caso de concurrir diferentes foros de aplicación, cuál de ellos resulta el más adecuado, ágil y eficaz para hacer valer las acciones judiciales que, en relación con la pensión de alimentos, se pretendan ejercitar.

4. En el contexto apuntado, se inscribe el auto de la Sala de lo Civil del Tribunal Supremo número 9225/2019, de 17 de septiembre de 2019, Ponente don Eduardo Baena Ruiz, objeto de este estudio1. Los hechos son sencillos. Se interpone, ante tribunales españoles, una demanda de modificación de las medidas adoptadas en sentencia de divorcio dictada por un órgano jurisdiccional de Rumanía. La demanda la interpone la madre -que reside en España con su hija menor de edad- frente al padre de dicha menor, que tenía su domicilio en Madrid, y en relación al importe de la pensión alimenticia y reparto de diferentes gastos relativos a la menor.

5. El Juzgado de Primera Instancia español ante el que la madre interpone la demanda de modificación de medidas entiende que no es competente territorialmente para su conocimiento. En consecuen-

\footnotetext{
${ }^{1}$ ATS 17 septiembre 2019 [ECLI:ES:TS:2019:9225A] y [CENDOJ 28079110012019203694].
} 
cia, se inhibe a favor del Juzgado de Primera Instancia también español correspondiente al domicilio del padre demanda, por aplicación del art. 769 LEC.

Por su parte, el juzgado del domicilio del demandado considera que la competencia territorial corresponde al juzgado de Primera Instancia donde la hija menor de edad tiene establecido su domicilio, en virtud del art. 769.3 LEC, en relación con el art. 3 del Reglamento (CE) núm. 4/2009 del Consejo de 18 diciembre 2008 relativo a la competencia, la ley aplicable, el reconocimiento y la ejecución de las resoluciones y la cooperación en materia de obligaciones de alimentos ${ }^{2}$.

Por tanto, dos Juzgados de Primera Instancia españoles declaran su falta de competencia territorial para el conocimiento de la demanda de modificación de medidas en materia de alimentos y contenidas en una sentencia dictada en Rumanía. Las actuaciones se remiten, pues, al Tribunal Supremo para que resuelva sobre el conflicto negativo de competencia planteado.

6. La competencia territorial en los procesos civiles ante la jurisdicción española que versan sobre alimentos de menores $\mathrm{y}$, en general, la competencia territorial en los procedimientos de familia tramitados conforme a los trámites del juicio verbal, se rige por reglas imperativas, no disponibles por las partes. Así se desprende del art. 769.3 y 4 LEC y del art. 770 LEC, en relación éste último con el 54.1 LEC.

Ello determina, por un lado, que la competencia territorial haya de ser examinada, inmediatamente después de presentada la demanda, de oficio por el letrado de la administración de justicia (art. 58 LEC), quien podrá dar cuenta al juez para que resuelva lo que proceda mediante auto si entiende que el tribunal carece de competencia territorial para conocer del asunto.

Por otro lado, cuando se está en presencia de competencia territorial fijada por normas imperativas, el tribunal ante el que se propone la demanda -en el presente caso de modificación de medidas acordadas inicialmente en sentencia de divorcio-, puede decidir su falta de competencia territorial con sólo oír al Ministerio Fiscal y a las partes personadas. Esto es, el tribunal podrá inhibirse del conocimiento del asunto por su falta de competencia territorial una vez que haya dado audiencia únicamente al Ministerio Fiscal y al actor, y no al demandado, puesto que el examen de dicha competencia se realizará con carácter previo a la admisión a trámite de la demanda y, por ende, con anterioridad a la personación del demandado.

7. A este supuesto se ajusta el caso analizado por el auto del Tribunal Supremo de 17 de septiembre de 2019. Es decir, se trata de un procedimiento ante la jurisdicción española sobre modificación de medidas de alimentos en el que la competencia territorial viene fijada por normas imperativas y el tribunal ante el que se presenta la demanda declara su falta de competencia territorial sin audiencia de todas las partes implicadas en el procedimiento. Es, por tanto, el supuesto previsto en el apartado 2 del art. 60 LEC, según el cual "Si la decisión de inhibición por falta de competencia territorial no se hubiese adoptado con audiencia de todas las partes, el tribunal a quien se remitieran las actuaciones podrá declarar su falta de competencia territorial, cuando ésta deba determinarse en virtud de reglas imperativas".

En consecuencia, declarada la falta de competencia territorial del primer tribunal español ante el que se plantea la demanda de modificación de las medidas relativas a los alimentos de la hija menor, el segundo tribunal -español, igualmente- al que se remiten las actuaciones para el conocimiento del asunto, puede también declarar de oficio su falta de competencia territorial. Y así lo hace.

El trámite procesal posterior es el establecido en al apartado 3 del art. 60 LEC: cuando dos órganos jurisdiccionales civiles españoles entienden que no son competentes territorialmente para conocer de un asunto y se inhiben de su conocimiento -como ocurre en el supuesto objeto de estudio-, se genera el incidente procesal de conflicto negativo de competencia territorial. De conformidad con lo previsto en dicho precepto, ambos tribunales españoles tienen obligación de remitir todas las actuaciones al órgano superior común a fin de que dirima la controversia. En este caso, el tribunal superior común a los dos juzgados de primera instancia que declaran su falta de competencia territorial es el Tribunal Supremo.

Contra el auto del Tribunal Supremo que resuelve sobre la competencia territorial de dos tribunales españoles no cabe recurso alguno (art. 67 LEC).

${ }^{2}$ DOUE L 7 de 10 enero 2009. 


\section{Primer nivel normativo. Competencia internacional y Reglamento (CE) 4/2009, de 18 de di- ciembre de 2008}

8. Para resolver el conflicto negativo de competencia, el auto del Tribunal Supremo de 17 septiembre 2019, arranca, muy correctamente, de un primer nivel normativo, el correspondiente a la competencia internacional. La sentencia de divorcio que establece las medidas definitivas relativas a los alimentos de la hija menor, cuya modificación ahora se pretende ante la jurisdicción española, fue dictada por un juzgado de Rumanía. En este sentido, se trata de un litigio internacional o transfronterizo, de modo que para determinar la competencia internacional de los órganos jurisdiccionales españoles, el Tribunal Supremo recurre acertadamente a la aplicación del citado Reglamento (CE) 4/2009, de 18 de diciembre de 2008. El art. 3 a) y b) de dicho instrumento normativo determina que la competencia para resolver en materia de obligaciones de alimentos será la del juzgado del Estado miembro de la UE donde el demandado tenga su residencia habitual o donde el acreedor de los alimentos tenga su residencia habitual ${ }^{3}$. Se trata de foros alternativos, por lo que el actor puede presentar su demanda ante uno u otro tribunal, según prefiera ${ }^{4}$. En ambos casos, la competencia corresponde a los tribunales españoles: en España está la residencia habitual del demandado y en España está también la residencia habitual del acreedor de alimentos.

9. Por tanto, y en aplicación del art. 3 a) y b) del Reglamento 4/2009, los tribunales españoles resultan competentes para el conocimiento de la demanda de modificación de la medida de alimentos establecida en sentencia de divorcio dictada por un juzgado de Rumanía. Y ello tanto si se opta por la residencia habitual del demandado (art. 3.a) R.4/2009), como si finalmente se elige el foro de la acreedora de los alimentos (Art. 3.b) R.4/2009).

10. Algunos datos preliminares deben también subrayarse para comprender en su justa medida el alcance del Reglamento 4/2009 en relación con este caso.

En primer término, el Tribunal Supremo destaca en éste su auto de 17 de septiembre de 2009 que, en la labor integradora del Derecho Internacional Privado al caso concreto objeto de estudio, no resulta de aplicación el Reglamento (CE) 2201/2003, de 27 de noviembre, relativo a la competencia, el reconocimiento y la ejecución de resoluciones judiciales en materia matrimonial y de responsabilidad parental, esto es, el Reglamento Bruselas II-bis ${ }^{5}$. El art. 1.3. e) RB II-bis, en efecto, excluye de su ámbito de aplicación material las obligaciones de alimentos ${ }^{6}$.

En segundo término, como ha señalado J. CARrascosa González, el Reglamento 4/2009 sustituye las disposiciones del Reglamento 44/2001 aplicables en materia de obligaciones de alimentos (art. 68 R. 4/2009) a partir de su entrada en vigor, que se produjo el 30 enero 2009, y de su momento inicial

\footnotetext{
${ }^{3}$ Artículo 3 R.4/2009: "Disposiciones generales. Serán competentes para resolver en materia de obligaciones de alimentos en los Estados miembros:

a) el órgano jurisdiccional del lugar donde el demandado tenga su residencia habitual, o

b) el órgano jurisdiccional del lugar donde el acreedor tenga su residencia habitual, o

c) el órgano jurisdiccional competente en virtud de la ley del foro para conocer de una acción relativa al estado de las personas, cuando la demanda relativa a una obligación de alimentos sea accesoria de esta acción, salvo si esta competencia se basa únicamente en la nacionalidad de una de las partes, $o$

d) el órgano jurisdiccional competente en virtud de la ley del foro para conocer de una acción relativa a la responsabilidad parental, cuando la demanda relativa a una obligación de alimentos sea accesoria de esta acción, salvo si esta competencia se basa únicamente en la nacionalidad de una de las partes".

${ }^{4}$ B. Ancel / H. Muir WatT, "Aliments sans frontières. Le règlement CE n ${ }^{\circ} .4 / 2009$ du 18 décembre 2008 relatif à la compétence, la loi applicable, la reconnaissance et l'exécution des décisions et la coopération en matière d'obligations alimentaires", RCDIP, 2010, pp. 457-484.

${ }^{5}$ Reglamento (CE) 2201/2003 del Consejo de 27 noviembre 2003 relativo a la competencia, el reconocimiento y la ejecución de resoluciones judiciales en materia matrimonial y de responsabilidad parental, por el que se deroga el Reglamento (CE) $n^{\circ}$ 1347/2000 (DOUE L 338 de 23 diciembre 2003) (Reglamento Bruselas II-bis).

${ }^{6}$ E. Castellanos Ruiz, "La obligación de alimentos en Derecho internacional privado" en M. IzQuierdo / M. Cuena (dirs.), Tratado de Derecho de La Familia, vol. I, Aranzadi, Navarra, 2011, pp. 319-426.
} 
de aplicación, que tuvo lugar el 18 junio $2011^{7}$. En todo caso, es preciso traer a la memoria que el Reglamento 44/2001 ha sido derogado por el Reglamento Bruselas I-bis (2012), texto que no es aplicable al sector de los alimentos.

En tercer lugar, es necesario tener presente que los foros recogidos en el Reglamento 4/2009 relativos a los litigios de alimentos operan de manera separada e independiente ${ }^{8}$. Ello significa que un tribunal de un Estado miembro puede o no ser competente para decidir el divorcio de los progenitores de un menor, la responsabilidad parental respecto de ese menor y la obligación de alimentos hacia éste, con arreglo a normas distintas de competencia internacional, de modo que puede disponer de competencia para resolver una, dos o las tres cuestiones anteriores de manera independiente ${ }^{9}$. Así lo ha precisado la STJUE 5 septiembre 2019, C-468/18, $R$ vs. $P$ FD 51-52 ${ }^{10}$.

En cuarto lugar, también es conveniente no olvidar que los foros recogidos en el Reglamento $4 / 2009$ y relativos a los litigios de alimentos funcionan tanto para las demandas declarativas que se interponen para reclamar de alimentos como para las demandas de modificación de resoluciones de alimentos ya dictadas por un órgano jurisdiccional ${ }^{11}$. Así lo ha apuntado la STJUE 15 febrero 2017, C-499/15, $W, V v s . X^{12}$. As, en el mismo sentido, se ha pronunciado el AAP Valencia 15 junio 2010 [posible extinción de alimentos de madre e hija con residencia habitual en Austria] y la SAP Barcelona 15 septiembre 2010 [modificación de sentencia rumana de divorcio]) ${ }^{13}$. Este dato pone de relieve que el "estado de cosas en Derecho" creado por una sentencia dictada por un tribunal de un Estado miembro se mantiene en los demás Estados miembros. Y a partir de ahí, se puede modificar, pero se arranca de una base indiscutible: lo fallado por la sentencia pronunciada por tribunales de otro Estado miembro, apunta S.L. GössL ${ }^{14}$.

En quinto lugar, estos foros también son aplicables a los litigios relativos a la extinción de alimentos como ha observado perspicazmente M. VARGAS GómEZ-URRUTIA ${ }^{15}$.

7 J. Carrascosa González, "Alimentos", en A.-L. Calvo Caravaca / J. Carrascosa González (Directores), Derecho internacional privado, vol. II, $18^{a}$ edición, Comares, Granada, 2018, pp. 542-543.

${ }^{8}$ A. DAvì / A. ZANOBETTI, "Le obbligazioni alimentari tra parti di un'unione civile e tra conviventi nel diritto internazionale privato", Rivista trimestrale di diritto e procedura civile, 2017-1, pp. 197-211.

${ }^{9} \mathrm{~N}$. JOUBERT, "L'exécution des décisions entre autonomie procédurale des Etats membres et pleine efficacité du règlement Aliments. CJUE (6è ch.), 9 février 2017 aff. C-283/16", RCDIP, 2017-4, pp. 568-572.

${ }^{10}$ STJUE 5 septiembre 2019, C-468/18, R vs. P [ECLI:EU:C:2019:666], FD 51: "Numerosas razones, como las mencionadas por el Abogado General en los puntos 65 a 71 de sus conclusiones, pueden motivar tal elección del acreedor de alimentos, en particular, la posibilidad de que se aplique la ley del foro, en el caso de autos la ley rumana, la facilidad de expresarse en su lengua materna, los costes posiblemente menores del procedimiento, el conocimiento de la capacidad económica del demandado por parte del órgano jurisdiccional ante el que se ha interpuesto la demanda y la eventual dispensa del exequátur" y FD 52: "Por consiguiente, procede responder a las cuestiones planteadas que el artículo 3, letras a) y d), y el artículo 5 del Reglamento n. ${ }^{\circ}$ 4/2009 deben interpretarse en el sentido de que, en caso de que ante un órgano jurisdiccional de un Estado miembro se interponga un recurso que comprende tres pretensiones relativas, respectivamente, al divorcio de los progenitores de un menor, a la responsabilidad parental respecto de ese menor y a la obligación de alimentos hacia este, el órgano jurisdiccional que resuelve sobre el divorcio y que se ha declarado incompetente para pronunciarse sobre la pretensión relativa a la responsabilidad parental es competente, sin embargo, para resolver sobre la pretensión relativa a la obligación de alimentos respecto a dicho menor, cuando es también el órgano jurisdiccional del lugar de la residencia habitual del demandado o el órgano jurisdiccional ante el que este ha comparecido, sin impugnar su competencia".

${ }^{11} \mathrm{~N}$. Joubert, "La résidence de l'enfant du divorce face à la demande de modification de la décisions relative á la garde et aux aliments" (nota a Sent. TJUE 15 febrero 2017, C-499/15)", RCDIP, 2018-1, pp. 138-143.

${ }^{12}$ STJUE 15 febrero 2017, C-499/15, W, V vs. X [ECLI:EU:C:2017:118].

13 AAP Valencia 15 junio 2010 [CENDOJ 46250370102010200272]; SAP Barcelona 15 septiembre 2010 [CENDOJ 08019370122010100317].

${ }^{14}$ S.L. GössL, "Ein weiterer Mosaikstein bei der Anerkennung ausländischer Status-Änderungen in der EU oder: Wann ist ein Name „rechtmäßig erworben“? (EuGH S. 416)", IPRax, 2018-4, pp. 376-381.

${ }^{15}$ M. VARGas GómeZ-URrutia, "Litigios sobre la obligación de alimentos: normas de competencia y problemas procesales en el Reglamento 4/2009", en M. GuZmÁn Zapater y M. Herranz Ballesteros (dir.), Crisis matrimoniales internacionales y sus efectos: derecho español y de la Unión Europea: estudio normativo y jurisprudencial, 2018, pp. 317-352. 


\section{Segundo nivel normativo: Competencia territorial de los tribunales españoles. Ley 1/2000, de 7 de enero, de Enjuiciamiento Civil.}

11. Superado el primer nivel normativo, y afirmada la indiscutible competencia internacional de los órganos jurisdiccionales españoles para el conocimiento del asunto, el auto del Tribunal Supremo de 17 de septiembre de 2019 aborda el segundo nivel normativo, relativo a la competencia territorial de los tribunales españoles. En este segundo estrato legal, el TS hace uso de la LEC (Ley 1/2000, de 7 de enero, de Enjuiciamiento Civil) ${ }^{16}$. Y es, precisamente, en el ámbito de la ley procesal civil española donde surgen los controvertidos problemas interpretativos de los arts. 775 y 769.3, ambos de la LEC, especialmente tras la nueva redacción dada al art. 775 LEC por la Ley 42/2015, de 5 de octubre.

a) El nuevo marco de competencia territorial del art. 775 LEC, en su redacción ofrecida por la Ley 42/2015, de 5 de octubre.

12. El art. 775 LEC, en su redacción dada por la Ley $42 / 2015$, de 5 de octubre, de reforma de la Ley 1/2000, de 7 de enero, de Enjuiciamiento Civil, determina:

“(...) El Ministerio Fiscal, habiendo hijos menores o incapacitados y, en todo caso, los cónyuges, podrán solicitar del tribunal que acordó las medidas definitivas, la modificación de las medidas convenidas por los cónyuges o las adoptadas en defecto de acuerdo, siempre que hayan variado sustancialmente las circunstancias tenidas en cuenta al aprobarlas o acordarlas (...)" (cursivas añadidas) ${ }^{17}$.

13. En su redacción primitiva, bajo la rúbrica "Modificación de las medidas definitivas", el art. 775 LEC presentaba en su primer apartado el siguiente tenor:

“(...) El Ministerio Fiscal, habiendo hijos menores o incapacitados y, en todo caso, los cónyuges, podrán solicitar del tribunal, la modificación de las medidas convenidas por los cónyuges o las adoptadas en defecto de acuerdo, siempre que hayan variado sustancialmente las circunstancias tenidas en cuenta al aprobarlas o acordarlas (...) "(cursivas añadidas).

14. El auto del Tribunal Supremo de 17 de septiembre de 2019 argumenta respecto a la competencia territorial que ha de regir en los procedimientos de modificación de medidas definitivas que se tramiten ante los tribunales españoles a partir de la modificación operada por la Ley 42/2015, que el art. 775 LEC goza, en los casos internos en los que es preciso concretar la competencia territorial, de "preferencia aplicativa" sobre el art. $769.3 \mathrm{LEC}^{18}$.

\footnotetext{
${ }^{16}$ Ley 1/2000, de 7 de enero, de Enjuiciamiento Civil, publicada en BOE núm. 7, de 8/01/2000

${ }^{17}$ Ley 42/2015, de 5 de octubre, de reforma de la Ley 1/2000, de 7 de enero, de Enjuiciamiento Civil, publicada en BOE núm. 239, de 6 de octubre de 2015, pp. 90240 a 90288.

${ }^{18}$ Indica el TS: "C) Esta Sala, con anterioridad a la reforma procesal del art. 775 LEC, por la Ley 42/2015, de 5 de octubre, habia venido determinando, respecto a las demandas de modificación de medidas definitivas en relación con el régimen de visitas, guarda y custodia y pensión de alimentos de los hijos menores que éstas se regían por la regla de competencia determinada en el art. 769.3 LEC, al considerar que el proceso de modificación de medidas no era un incidente del pleito principal, sino un procedimiento autónomo en cuanto a las reglas de competencia se refería (AATS de 27 de enero de 2016, conflicto $n^{\circ}$ 224/2015 y 24 de febrero de 2016, conflicto $n^{\circ} 239 / 2015$, entre los más recientes). D) Sin embargo, tras la entrada en vigor de la nueva redacción del art. 775 LEC, por la Ley 42/2015, de 5 de octubre, esta sala ha venido aplicando el tenor literal de este precepto, atribuyendo la competencia para conocer de las demandas de modificación de medidas al juzgado que dictó la resolución inicial (Auto del Pleno de 27 de junio de 2016, asunto 815/2016) Respecto a esta solución, la sala ha recordado que no se trata ésta de una medida aislada adoptada por esta reforma legislativa, pues la coetánea Ley 15/2015, de 2 de julio, de la Jurisdicción Voluntaria, mantuvo el mismo criterio: el fuero general en los expedientes de intervención judicial por desacuerdo en el ejercicio de la patria potestad, en los de medidas de protección relativos al ejercicio inadecuado de la potestad de guarda y en los de la administración de bienes de menores de las personas con la capacidad modificada es el de su domicilio (arts. 86.2 y 87.2), pero se regulan en esos mismos preceptos concretas excepciones que atribuyen la competencia de forma prioritaria al juzgado que previamente haya dictado una resolución estableciendo el ejercicio conjunto de la patria potestad, la atribución de la guarda y custodia o la tutela. Por lo demás, ha recordado la sala, que el principio de proximidad no es absoluto en el
} 
15. Ello significa que, con anterioridad a la reforma introducida por la Ley $42 / 2015$, de 5 de octubre, la competencia territorial en los procedimientos de modificación de medidas definitivas (que versaran sobre guarda y custodia de hijos menores o sobre alimentos reclamados por un progenitor contra el otro en nombre de los hijos menores) se regía por el art. 769.3 LEC $^{19}$. De este modo, y de conformidad con doctrina consolidada por el Tribunal Supremo, cuando existían unas medidas definitivas previas y las partes, o incluso los menores procedían a cambiar su domicilio, al formular una modificación de las medidas, el superior interés de los menores implicaba seguir una solución acorde con el principio de proximidad. Y en consecuencia, resultaban competentes, a elección del demandante (fuero imperativo, pero electivo) el Juzgado de Primera Instancia (o el Juzgado de Familia) del domicilio del demandado o el correspondiente a la residencia del menor. En otro caso, esto es, cuando los progenitores residían en el mismo partido, resultaba competente el Juzgado del lugar del último domicilio común.

16. Sin embargo, la reforma del art. 775 LEC introducida por la Ley $42 / 2015$, de 5 de octubre, atribuye expresamente la competencia territorial para la tramitación de las demandas de modificación de medidas a partir de 7 de octubre de 2015 (fecha en que entra en vigor la modificación) al Juzgado que dictó la sentencia con las medidas definitivas. Es decir, al órgano que acordó las primigenias medidas, que será el Juzgado que tramitó la separación, el divorcio o las relaciones paterno-filiares, que "conserva" su competencia a pesar del cambio de circunstancias del supuesto (perpetuatio fori). Esta solución encaja con lo establecido en el art. 545.1 LEC para las resoluciones susceptibles de ejecución forzosa, y también con lo preceptuado en el art. 807 LEC para los procedimientos de liquidación del régimen económico-matrimonial. Es una solución también seguida por el art. 86.2 de la Ley 15/2015, de 2 de julio, de Jurisdicción Voluntaria, respecto de la competencia para conocer de las solicitudes de tutela en caso de desacuerdo en el ejercicio de la patria potestad y por el art. 87.2 de la misma Ley de Jurisdicción Voluntaria, respecto de los expedientes para la adopción de medidas relativas al ejercicio inadecuado de la potestad de guarda o de administración de los bienes del menor o persona con capacidad modificada judicialmente.

17. En apoyo de esta tesis surgida a partir de la nueva redacción del art. 775 LEC para la determinación de la competencia relativa a modificación de medidas definitivas, se alzan numerosas resoluciones del Tribunal Supremo. Todas ellas tienen como fundamento el Auto del Pleno de 27 de junio de 2016 (conflicto 815/2016), que sigue, a su vez, el criterio fijado en el Auto de 30 de marzo de 2016 (conflicto 42/2016), resoluciones que han sido reiteradas posteriormente mediante diferentes autos de la misma Sala Primera ${ }^{20}$.

18. En el Auto del TS de fecha 30 de marzo de 2016 (asunto 42/2016) se resolvió el conflicto de competencia en favor del juzgado que conoció del procedimiento inicial, con el argumento de que tras la reforma operada en el art. 775 LEC por la Ley 42/2015 "[...] ya no es aplicable la regla sobre atribución de competencia recogida en el art. 769.3 LEC, que la Sala Primera venía aplicando a las demandas de modificación de medidas definitivas en relación con el régimen de visitas, guarda y custodia y pensión de alimentos de los hijos menores al considerar que el proceso de modificación de medidas no era un

resto de los fueros de competencia de los procesos matrimoniales y de menores que regula la LEC y que, de hecho, ni el art. 769.1 ni el art. 769.3 LEC establecen como fuero principal el domicilio de los menores. Por todo ello, ha entendido esta sala, que en la opción plasmada por la reforma del art. 775 LEC el legislador ya ha ponderado las ventajas y los inconvenientes de una solución que, una vez convertida en derecho positivo, no puede ser obviada por los órganos judiciales que aplican la norma, por "exigencias básicas del principio de legalidad"...".

19 Art. 769.3 LEC, texto original publicado el 8/01/2000, en vigor a partir del 8/01/2001: "En los procesos que versen exclusivamente sobre guarda y custodia de hijos menores o sobre alimentos reclamados por un progenitor contra el otro en nombre de los hijos menores, será competente el Juzgado de Primera Instancia del lugar del último domicilio común de los progenitores. En el caso de residir los progenitores en distintos partidos judiciales, será tribunal competente, a elección del demandante, el del domicilio del demandado o el de la residencia del menor".

${ }^{20}$ Vid., ad ex.: ATS 22 marzo 2017 [ECLI: ES: TS: 2017:2563A]; ATS 20 julio 2016 [ECLI: ES: TS: 2016: 7582A]; ATS 14 septiembre 2016 [ECLI: ES: TS: 2016 :8171A]; ATS 21 diciembre 2016 [ECLI: ES: TS: 2016:11978A]; ATS 15 febrero 2017 [ECLI: ES: TS: 2017:840A]; ATS 14 febrero 2018 [ECLI: ES: TS: 2018: 1208A]; ATS 25 abril 2018 [ECLI: ES: TS: 2018:4789A]; ATS 17 julio 2018 [ECLI: ES: TS: 2018:8393A]; ATS 29 enero 2019 [ECLI: ES: TS: 2019:1565A]. 
incidente del pleito principal, sino un procedimiento autónomo en cuanto a las reglas de competencia se refería".

19. El Auto del Pleno de 27 de junio de 2016 (asunto 815/2016) del Tribunal Supremo ilustra ampliamente, y con todo acierto, sobre el nuevo marco de competencia territorial establecido por la nueva redacción del art. 775 LEC. Valga destacar aquí sus palabras más relevantes:

"Se entiende, por ello, que en la opción plasmada en la reforma del art. 775 el legislador ya ha ponderado las ventajas y los inconvenientes de una solución que, una vez convertida en derecho positivo, no puede ser obviada por los órganos judiciales que aplican la norma, por exigencias básicas del principio de legalidad. No puede desconocerse que, frente a la virtualidad indudable del fuero de proximidad, mantener la competencia del juzgado que adoptó las medidas cuya modificación se pretende aporta también ventajas y que los inconvenientes que provoca no son insalvables. En primer lugar, este fuero de competencia aporta un factor de calidad en la decisión de cambio de las medidas, ya que es el juzgado que las adoptó el que se encuentra en mejor posición para valorar si las circunstancias tenidas en cuenta en la resolución inicial han sufrido una modificación relevante. En segundo lugar, la atribución unívoca y exclusiva de la competencia a ese juzgado es una norma clara y precisa que garantiza la seguridad jurídica y evita conflictos de competencia como los que han sido tan frecuentes en la aplicación del art. 769 LEC, al tiempo que evita posibles fraudes de ley por alteraciones caprichosas del domicilio del progenitor custodio.

Por otro lado, los inconvenientes de esta solución, apuntados por el Ministerio Fiscal en su informe, se concentran en los concretos casos en que la modificación de las medidas afecte a hijos menores o discapaces que hayan dejado de residir en el partido judicial en el que se dictó la resolución inicial, pero, aun constatando el riesgo de que tales inconvenientes existan, no se consideran insalvables. De entrada, se trata de un problema que admite múltiples graduaciones en función del caso concreto: su entidad dependerá de la distancia entre ciudades, de las vías y medios de comunicación, de la residencia del progenitor no custodio, del régimen de estancia con él, de los vínculos con la ciudad de origen, etc., de modo que en muchos casos el asunto podrá tramitarse y resolverse en el juzgado que acordó las medidas sin especiales dificultades para los menores o discapaces. Y, en función de las peculiaridades de cada caso, siempre será posible arbitrar los medios necesarios para minimizar esos inconvenientes: la utilización del sistema de videoconferencia para la práctica de las pruebas personales, previsto en el art. 229 LOPJ para las «declaraciones, interrogatorios, testimonios, careos, exploraciones, informes, ratificación de los periciales y vistas»; la colaboración de los equipos psicosociales adscritos a los juzgados del domicilio del menor; las vías de cooperación y auxilio judicial previstas en la ley; incluso, cuando la exploración de los menores sea necesaria y resulte especialmente gravoso su desplazamiento al juzgado competente, podrá autorizarse el desplazamiento del juez de conformidad con el art. 275 LOPJ, cuando no se perjudique la competencia de otro órgano y venga justificado por razones de economía procesal".

20. En consecuencia, parece claro que, tras la reforma legal operada por la Ley $42 / 2015$, de 5 de octubre, la competencia territorial para los litigios para la modificación de medidas relativas a alimentos corresponde al Juzgado que dictó la sentencia con las medidas definitivas. Cierto, pero como es lógico, natural y evidente, esta regla de competencia territorial sólo funciona de modo correcto si el juzgado que dictó la sentencia sobre alimentos es un juzgado español. En efecto, el art. 775 LEC no recoge una regla de competencia territorial que decide el juzgado español que dispone de tal competencia al efecto. El precepto no puede, de ningún modo, atribuir la competencia territorial a un tribunal extranjero, por evidentes razones de soberanía. La determinación del exacto tribunal territorialmente competente para modificar una sentencia de alimentos es competencia de cada Estado.

\section{b) La regla de competencia territorial para asuntos con "elementos extranjeros". Entra al terreno de juego el art. 769 LEC}

21. El auto del Tribunal Supremo objeto de estudio se reafirma y se recrea en que es el art. 775 LEC, en su nueva redacción dada en el año 2015, el que debe presidir el marco de competencia terri- 
torial en las modificaciones de medidas establecidas como definitivas anteriormente, de modo que el conocimiento de las demandas de modificación de medidas relativas a alimentos corresponde, de modo imperativo, al juzgado que dictó la resolución inicial.

22. Sin embargo, este auto del Tribunal Supremo de 17 de septiembre de 2019 recuerda en su tercer y último fundamento de Derecho, que, en el caso objeto de estudio, la medida de alimentos fue adoptada originariamente en sentencia de divorcio por un juzgado de Rumanía. En consecuencia, manifiesta el Ponente de la resolución analizada la "imposibilidad de aplicar el art. 775 LEC al supuesto de autos", puesto que la medida definitiva de alimentos no fue acordada por un órgano jurisdiccional español. El Ponente insiste en que procede resolver el conflicto de competencia planteado mediante la aplicación del art. 769.3 LEC.

Es decir, en el caso analizado, el Tribunal Supremo termina por dar entrada al terreno de juego al art. 769.3 LEC y atribuye finalmente la competencia territorial de la modificación de medidas planteada al juzgado donde se encuentra el domicilio de la menor acreedora de los alimentos. En defensa de dicho criterio añade, como única motivación o justificación que tal decisión se adopta "de acuerdo con los criterios expuestos y seguidos por esta sala hasta la modificación del art. 775 LEC por la ley 42/2015, de 5 de octubre".

23. La cuestión de fondo que suscita el auto del Tribunal Supremo analizado es, por un lado, que la norma de competencia contenida en el art. 775 LEC, con los aciertos y desaciertos que la doctrina ha puesto de manifiesto respecto a su nueva redacción operada en el año 2015, es una regla de competencia territorial para asuntos sin "elementos extranjeros". En este sentido, únicamente se puede anclar la competencia del tribunal anterior que dictó resolución inicial sobre las medidas que se pretenden modificar si dicho órgano jurisdiccional fue originariamente un juzgado o tribunal español. Para el caso de medidas adoptadas en su origen en el seno de un procedimiento seguido ante un juzgado o tribunal extranjero, la regla de competencia territorial del art. 775 deviene no operativa y de imposible aplicación. Es preciso encontrar un juzgado español competente para modificar la resolución de alimentos dictada en Rumanía porque el Reglamento 4/2009 atribuye a los tribunales españoles la competencia internacional para conocer de tal modificación.

24. Por otro lado, resulta criticable en el auto objeto de análisis que no se profundice ni se justifique la atribución de competencia al juzgado donde se encuentra el domicilio de la menor, pues obvia así otra de las reglas de competencia contenidas en el art. 769.3 LEC. Con ello se hace alusión al olvidado, por el TS, foro del domicilio del demandado, ya que de la dicción literal del art. 769.3 LEC se colige que, en los casos en que los progenitores residan en distintos partidos judiciales, -circunstancia que es muy habitual en los asuntos con elemento internacional-, "será tribunal competente, a elección del demandante, el del domicilio del demandado o el de la residencia del menor". Se trata de foros alternativos, de manera que puede elegirse entre uno u otro, según convenga a la demandante en su estrategia procesal.

25. Por razones obvias, puede ser más conveniente, cómodo y sencillo interponer demanda de modificación de medidas de alimentos ante el juzgado español que corresponde al lugar donde tiene su residencia la menor, que convive junto con la madre, la demandante. La tramitación del procedimiento ante el Juzgado donde residen madre e hija evita el desplazamiento de ambas a otras localidades más lejanas y supone un ahorro en los gastos del procedimiento, por no hablar de la cercanía y agilidad que supone litigar con abogado y procurador de la propia plaza judicial. Sin duda, la elección del lugar de residencia de la menor como foro de competencia territorial redunda en una buena administración de justicia, en términos de oportunidad y economía e incluso celeridad del procedimiento.

26. Sin embargo, frente a lo anterior, el auto del Tribunal Supremo de 17 de septiembre de 2019 se queda a medio camino. No zanja definitivamente la controversia que se suscita cuando el asunto reviste un carácter internacional y está provisto de "elementos extranjeros". Este carácter internacional, la mayor parte de las veces, comporta que los domicilios de los progenitores no se localicen en la misma 
población. La Sala no explica en estos casos el juego alternativo vía art. 769.3 LEC del domicilio del demandado y de la residencia de la menor acreedora de los alimentos, a elección de la demandante. Se trata de unos foros alternativos que se encuentran en línea y en franca consonancia con los foros aplicados por la misma resolución del Tribunal Supremo como primer nivel normativo, es decir, en el ámbito de la competencia internacional. Y ello porque la competencia internacional de los órganos jurisdiccionales españoles resulta de la dispuesto en el art. 3 a) y b) del Reglamento (CE) 4/2009, de 18 de diciembre de 2008, y se corresponde con los tribunales del Estado miembro donde tiene su residencia habitual el demandado o donde el acreedor de los alimentos tiene su residencia habitual.

27. Así, el objetivo de la norma de competencia territorial establecida en el art. 769.3 LEC para los asuntos con elementos extranjeros parece encontrarse, de esta manera, en íntima conexión con el fin de la norma contenida en los foros de competencia del art. 3 a) y b) del Reglamento 4/2009. Esta argumentación podría tener más peso que la ofrecida por el auto de 17 de septiembre de 2019, que parece estar anclado a un criterio unívoco de legeforismo que acude únicamente a la ley nacional interna para regular la situación privada internacional, e ignora, en consecuencia, la presencia de elementos extranjeros en el asunto.

28. En definitiva, no es que la competencia territorial de los juzgados españoles para modificar sentencias extranjeras relativas a alimentos venga determinada de forma subsidiaria en el art. 769.3 LEC, vista la imposibilidad de aplicación de la regla general que para dicha competencia viene determinada en el art. 775 LEC. Muy al contrario de ello, el art. 775 LEC está diseñado para asuntos nacionales que no presentan elemento internacional y en los que ha intervenido previamente un tribunal español en la fijación de las medidas definitivas que pretenden modificarse. Para casos con elementos extranjeros, en los que los tribunales que dictaron las medidas definitivas de alimentos no son tribunales españoles, la regla general debe ser la contenida en el art. 769.3 LEC. De esta manera, y por la vía de la aplicación del art. 769.3 LEC, se conecta, igualmente, con la evolución normativa de dicho precepto, de su labrado ajuste jurisprudencial antes de la reforma operada por la Ley 42/2015, de 5 de octubre. En efecto, la modificación de medidas se debe considerar como un procedimiento autónomo e independiente del inicial y no incidental del mismo. Además, de esa manera se tienen presentes las circunstancias actuales de las partes, que en la mayor parte de los asuntos ya no mantendrán relación alguna con el juzgado que originariamente dictó aquellas medidas.

\section{Una realidad alternativa. Los foros del Reglamento 4/2009 como foros de competencia inter- nacional y también territorial}

29. Acierta, es claro, el TS al entender que el art. 775 LEC no es aplicable a casos internacionales de modificación de medidas de alimentos originariamente acordadas por resoluciones dictadas por tribunales extranjeros ${ }^{21}$. La solución que el TS propone, esto es, acudir al juzgado español de la residencia del menor, produce consecuencias positivas, pero no debería el TS haber olvidado el otro foro territorial alternativo recogido en el art. 769.3 LEC, el domicilio del demandado. Dicho esto, otra visión del problema de la determinación de los tribunales españoles competentes para modificar sentencias extranjeras de alimentos es posible.

30. Una solución radicalmente distinta al problema, en efecto, y que puede proporcionar resultados más satisfactorios pasa por recordar que los dos foros recogidos en el art. 3 (letras a y b) del Reglamento 4/2009 (foro del "lugar donde el demandado tenga su residencia habitual" y foro del "lugar donde el acreedor tenga su residencia habitual"), son foros con doble valencia. Operan, en efecto, como foros de competencia internacional y como foros de competencia territorial al mismo tiempo.

${ }^{21}$ En tal sentido, R. Lacueva Bertolacci, "La ejecución de las resoluciones de alimentos previstas en el Reglamento (CE) núm. 4/2009 del Consejo”, La Ley (Unión Europea), n. 7747 de 30 noviembre 2011. 
Por tanto, el si el menor acreedor de alimentos tiene su residencia habitual, por ejemplo, en Santander, podrá acudir, ante los juzgados de Santander para solicitar la modificación de unos alimentos fijados anteriormente por sentencia dictada en Rumanía y ello por aplicación directa del art. 3.b R.4/2009, sin que resulte preciso aplicar la Ley de enjuiciamiento civil española 1/2000.

31. La doctrina acepta que estos dos foros contenidos en el art. 3.a y b R.4/2009 operan como una regla de competencia internacional y también como una regla de competencia territoria ${ }^{22}$. Así lo ha apuntado también, de manera transparente, la STJUE 18 diciembre 2014, C-400/13-C-408/13, Sophia Marie Nicole Sanders ${ }^{23}$. De todos modos, conviene tener presente que el TJUE ha indicado que la precisión exacta del órgano jurisdiccional concretamente competente para resolver tales litigios y la definición concreta de la competencia territorial de los órganos jurisdiccionales del lugar de residencia habitual del acreedor, corresponde a cada Estado miembro (STJUE 18 diciembre 2014, C-400/13 y C-408/13, Sanders, FD 30-31, citada). Por ejemplo, la precisión del partido judicial competente. El Estado miembro en cuestión debe señalar como competente un tribunal que corresponda, realmente, al lugar donde el acreedor tiene su residencia habitual o al lugar donde tiene su residencia habitual el demandado. Ello potencia, es evidente, el papel de la residencia habitual como foro eficiente de competencia internacional, observa M.-P. WELLER, como foro útil para los particulares afectados por una litigación internacional en el sector de los alimentos ${ }^{24}$.

32. Es curioso señalar que el Tribunal Supremo español encuentra dificultades a la hora de comprender la doctrina de los foros de doble valencia también en otros sectores y no sólo en relación con los alimentos y con el Reglamento 4/2009. Así, en un sector tan alejado de la esfera alimenticia como es el de la precisión del tribunal territorialmente competente para conocer de las reclamaciones de los particulares perjudicados por un cártel de dimensión transfronteriza, el Tribunal Supremo no alcanza a entender que el art. 7.2 del Reglamento Bruselas I-bis contiene, también un "foro de doble valencia" que determina la competencia internacional de los tribunales de un concreto Estado miembro y la competencia territorial de un tribunal específico de dicho Estado miembro ${ }^{25}$. Así lo ha destacado M. GómEz Jene, con precisión y argumentos irrebatibles ${ }^{26}$. En suma, el Tribunal Supremo entiende bien el conflicto de

${ }^{22}$ En esta dirección, vid., inter alia, E. Castellanos Ruz, Derecho de Alimentos. Aspectos Internacionales y Transfronterizos, Tirant lo Blanch, 2017, pp. 89-91; E. Castellanos Ruiz, "La obligación de alimentos en Derecho internacional privado" en M. Izquierdo / M. Cuena (dirs.), Tratado de Derecho de La Familia, vol. I, Aranzadi, Navarra, 2011, pp. 319-426; F. PocAr / I. VIARENGO, "Il Regolamento (CE) n.4 / 2009 in materia di obbligazioni alimentari", RDIPP, 2009, pp. 806-828; I. VIARENGO, "Rapporto sull'applicazione in Italia del Regolamento (CE) n. 4/2009 del 18 dicembre 2008 relativo alla competenza, alla legge applicabile, al riconoscimento e all'esecuzione delle decisioni e alla cooperazione in materia di obbligazioni alimentari", en S. BARIATTI/I. ViaRengo/F.C. Villata (EDS.), La giurisprudenza italiana sui regolamenti europei in materia civile e commerciale e di familia, Milanofiori Assago, Wolters Kluwer Italia, Padova, CEDAM, 2016, pp. 405-417; B. Ancel / H. Muir Watt, "Aliments sans frontières. Le règlement $\mathrm{CE} \mathrm{n}^{\circ} .4 / 2009 \mathrm{du} 18$ décembre 2008 relatif à la compétence, la loi applicable, la reconnaissance et l'exécution des décisions et la coopération en matière d'obligations alimentaires", $R C D I P, 2010$, pp. 457-484.

${ }^{23}$ STJUE 18 diciembre 2014, C-400/13-C-408/13, Sophia Marie Nicole Sanders, [ECLI:EU:C:2014:2461], FD 30: "El articulo 3, letra b), del Reglamento $n^{\circ}$ 4/2009 determina el criterio que permite identificar el órgano jurisdiccional competente para pronunciarse sobre los litigios transfronterizos relativos a obligaciones de alimentos, a saber, "el lugar donde el acreedor tenga su residencia habitual». Esta disposición, que determina tanto la competencia internacional como la competencia territorial, tiene por objeto unificar las reglas de conflicto de jurisdicción (véase, por analogía, la sentencia Color Drack, C-386/05, EU:C:2007:262, apartado 30)" y FD 31: "En sus observaciones escritas presentadas al Tribunal de Justicia, el Gobierno alemán y la Comisión ponen de relieve que aunque el artículo 3, letra b), del Reglamento $n^{\circ} 4 / 2009$ determina la competencia internacional y territorial de los órganos jurisdiccionales competentes para conocer de los litigios transfronterizos relativos a los créditos alimenticios, incumbe únicamente a los Estados miembros, en el marco de su organización jurisdiccional, identificar el órgano jurisdiccional concretamente competente para resolver tales litigios y definir la competencia territorial de los órganos jurisdiccionales del lugar de residencia habitual del acreedor en el sentido del artículo 3, letra b), del Reglamento no 4/2009".

${ }^{24}$ M.-P.WelLER, "DieneueMobilitätsanknüpfungim InternationalenFamilienrecht-Abfederung des Personalstatutenwechsels über die Datumtheorie", IPRax, 2014-3, pp. 225-233.

${ }^{25}$ Reglamento (UE) n. 1215/2012 del Parlamento Europeo y del Consejo de 12 de diciembre de 2012 relativo a la competencia judicial, el reconocimiento y la ejecución de resoluciones judiciales en materia civil y mercantil (refundición) (DOUE L 351 de 20 diciembre 2012), conocido como Reglamento Bruselas I-bis.

${ }^{26}$ M. Gómez Jene, "Competencia judicial internacional y litigación Camiones: sobre la aplicación del artículo 7.2 del Reglamento Bruselas I refundido", Diario La Ley, n 9410, 2019 (versión on line). 
jurisdicciones pero se maneja con aturdimiento e inexactitud cuando se trata de aplicar un foro europeo que es, al mismo tiempo, un foro de competencia internacional y un foro de competencia territorial, eso es, un foro propio del espacio de justicia europeo ${ }^{27}$.

\section{Reflexiones finales}

33. Diversas y de variada índole son las reflexiones que se pueden extraer de la resolución judicial analizada en este estudio.

En primer lugar, el Tribunal Supremo acierta al aplicar el art. art. 3.b Reglamento 4/2009 para fijar la competencia internacional de los juzgados españoles al caso analizado: es sin duda, una reclamación alimenticia con carácter internacional y el reglamento aludido es aplicable. Igualmente, vuelve a estar inspirado el Tribunal Supremo al descartar la aplicación al supuesto del art. 775 LEC. Es éste un precepto del Derecho procesal español que regula la competencia territorial de tribunales españoles una vez que ha quedado fijada la competencia internacional de la jurisdicción española. Por ello, el precepto citado no es aplicable a casos internacionales de modificación de medidas de alimentos originariamente acordadas por resoluciones dictadas por tribunales extranjeros.

En segundo lugar, y acreditada la competencia internacional de los jueces españoles para modificar una sentencia rumana que se pronuncia sobre alimentos debidos al menor, el Tribunal Supremo acude a la solución del foro territorial previsto en el art. 769.3 LEC. Es decir, el Tribunal Supremo acuerda declarar competente para el conocimiento del procedimiento de modificación de medidas de alimentos al juzgado español que se corresponde con la residencia del menor. Esta decisión es probablemente la más ventajosa en términos de oportunidad y economía e incluso de celeridad del procedimiento, puesto que se trata del tribunal más cercano a la menor y a su madre, con la que convive, y por ende, los gastos del procedimiento serán menores para la acreedora de los alimentos. Es loable, en este sentido, una decisión judicial que redunda en una buena administración de justicia.

En tercer lugar, el hecho de que el Tribunal Supremo acepte, tal y como marca el Derecho europeo, que un tribunal español puede y debe modificar, en su caso, una sentencia dictada por un tribunal de otro Estado miembro, Rumanía, es un reflejo positivo, subrayan C. KoHLER y M. Weller, del "principio de confianza mutua" en la Justicia que administran los aparatos judiciales de todos los Estados miembros de la $\mathrm{UE}^{28}$. Un juez de un Estado miembro dicta una sentencia y otro juez de otro Estado miembro la modifica.

34. Sin embargo, de una lectura más profunda de los fundamentos jurídicos de este auto del Tribunal Supremo de 17 de septiembre de 2019, puede concluirse que la resolución estudiada deja sin

\footnotetext{
${ }^{27}$ En estos casos, el TS mantiene una posición dudosa por no decir que cuestionable. Innumerables autos del alto tribunal ignoran que el art. 7.2 RB I-bis designa no sólo el Estado miembro cuyos tribunales son competentes para conocer del asunto, sino también, y al mismo tiempo, el concreto órgano jurisdiccional con competencia territorial al efecto. Así puede verse, por ejemplo, en el ATS 8 octubre 2019 [ECLI:ES:TS:2019:10149A], ATS 15 octubre 2019 [ECLI: ECLI:ES:TS:2019:10564A], ATS 22 octubre 2019 [ECLI:ES:TS:2019:10921A], ATS 5 noviembre 2019 [ECLI:ES:TS:2019:11489A], ATS 5 noviembre 2019 [ECLI:ES:TS:2019:12031A], ATS 12 noviembre 2019 [ECLI:ES:TS:2019:11930A], ATS 26 noviembre 2019 [ECLI:ES:TS:2019:12547A], ATS 26 noviembre 2019 [ECLI:ES:TS:2019:12520A], ATS 26 noviembre 2019 [ECLI:ES: TS:2019:12552A], ATS 3 diciembre 2019 [ECLI:ES:TS:2019:12964A], ATS 10 diciembre 2019 [ECLI:ES: TS:2019:12960A], entre otros muchos. Afirma el TS que el art. 7.2 RB I-bis sólo conduce a los tribunales españoles en el caso de que el camión se haya adquirido en España pero que la competencia territorial se determina mediante la LEC, lo que no es cierto ni necesario. En tal perspectiva, visto que el art. 52.1.12 ${ }^{\circ}$ LEC conduce al tribunal del lugar donde el demandado tiene su establecimiento y éste no tiene establecimiento en España ni tampoco domicilio o lugar de residencia, acude el TS al foro electivo para el demandante: lugar donde se haya realizado el acto o donde se produzcan sus efectos. Ello lleva a estimar relevante el lugar de producción de efectos, esto es, el lugar donde el demandante ve repercutido el sobreprecio, y que puede identificarse sin problemas adicionales con el lugar de adquisición del vehículo (art. 52.1.12 ${ }^{\circ}$ LEC). Este lugar es determinante como foro de competencia internacional en aplicación del art. 7.2 RB I-bis cuando el demandado no está domiciliado en España.

${ }^{28}$ C. KoHLER, "Grenzen des gegenseitigen Vertrauens im Europäischen Justizraum: Zum Urteil des EGMR in Sachen Avotiņš v. Lettland", IPRax, 2017-4, pp. 333-339; M. WeLLER, "Mutual trust: in search of the future of European Union private international law", Journal of Private International Law, vol. 11, 2015, pp. 64-102.
} 
explicar cuestiones clave en la aplicación el referido art. 769.3 LEC. Y ello porque olvida el juego del segundo foro territorial alternativo recogido en el indicado precepto, el del domicilio del demandado.

35. Deseable hubiera sido que el Tribunal Supremo hubiera entendido en el asunto objeto de análisis que las normas de competencia contenidas en el Reglamento 4/2009 operan como de competencia con "doble valencia". Porque el Tribunal Supremo, al aplicar el Reglamento 4/2009 se muestra europeísta y ello merece una valoración positiva. No obstante, si el Tribunal Supremo se sitúa en una línea europeísta, debería haber sido europeísta hasta el final, hasta sus últimas consecuencias. Y una de tales consecuencias radica en el hecho de que no sólo hay que aplicar el Derecho europeo, el Reglamento 4/2009 en este caso, sino que además es preciso descartar el Derecho español cuando no está en sintonía con el Derecho (internacional privado) europeo. En dicho sentido, el Tribunal Supremo olvida que el art. 3 , letras a) y b) del Reglamento 4/2009 recogen normas de competencia internacional y de competencia territorial al mismo tiempo: la doble valencia. Por tanto, el foro del "lugar donde el demandado tenga su residencia habitual" y el foro del "lugar donde el acreedor tenga su residencia habitual" son foros que operan como foros de competencia internacional y como foros de competencia territorial a la vez. Ésta hubiera sido la solución judicial que, por otro lado, habría encajado mejor con la buena administración de justicia, no sólo por las razones de economía y oportunidad indicadas para la demandante, sino también por las evidentes ventajas que comporta la consulta de un solo texto legal para saber cuál es el concreto tribunal competente para la modificación de medidas: en este caso, el Reglamento 4/2009. Los costes de información jurídica son también costes para las partes y el Derecho europeo, con estos foros, elimina la necesidad de consultar las normas de competencia territorial de los Estados miembros. En este sentido, el Tribnal Supremo debería "escuchar" al Tribunal de Justicia de la UE cuando éste interpreta y aplica los reglamentos europeos de DIPr. Ello redundaría, explican K. LENAERTS / Th. STAPPER, en una más ajustada aplicación del Derecho internaiconal privado europeo y en una mayor seguridad jurídica para los ciudadanos que circulan en el espacio europeo de Justicia ${ }^{29}$.

36. Hablar de futuro en la evolución jurisprudencial de estas normas de competencia con doble valencia y lograr con ello la aplicación de un único nivel normativo, el del Derecho de la Unión Europea, es siempre incierto y arriesgado. En un momento como el actual, en el que algunos países históricos de la Unión Europea ponen en tela de juicio los principios de autonomía y unidad que propiciaron un marco único de Derecho Internacional Privado en la Unión Europea, quizá lo más importante sea volver a creer profundamente en aquellos principios inspiradores del Derecho europeo y aplicarlos con toda su intensidad. En definitiva, resulta preciso, también para el Tribunal Supremo, volver a creer en el sistema institucional europeo, en el Espacio Europeo de Justicia, en el Derecho internacional privado de la Unión Europea como un sistema único de normas que hace Justicia en los casos transfronterizos que dinamiza, escriben H.-P. MANSEL / K. Thorn / R. WAgner, todo el Derecho europeo, y, por último, y muy particularmente, en el procedimiento de creación de normas jurídicas europeas y en el control de su validez e interpretación por parte del Tribunal de Justicia de la Unión Europea ${ }^{30}$.

${ }^{29}$ K. Lenaerts / Th. StapPer, "Die entwicklung der Brüssel I-Verordnung im Dialog des Europäischen Gerichtshofs mit dem Gesetzgeber", RabelsZ, 2014-1, pp. 252-293.

${ }^{30}$ H.-P. MAnsel / K. Thorn / R. WAGner, "Europäisches Kollisionsrecht 2010: Verstärkte Zusammenarbeit als Motor der Vereinheitlichung?", IPRax, 2011-I, pp. 1-30. 